Research

Open Access

\title{
Impact of emergency intubation on central venous oxygen saturation in critically ill patients: a multicenter observational study
}

\author{
Glenn Hernandez ${ }^{1}$, Hector Peña ${ }^{2}$, Rodrigo Cornejo ${ }^{3}$, Maximiliano Rovegno ${ }^{1}$, Jaime Retamal' ${ }^{1}$ \\ Jose Luis Navarro ${ }^{3}$, Ignacio Aranguiz ${ }^{1}$, Ricardo Castro ${ }^{1}$ and Alejandro Bruhn ${ }^{1}$
}

\author{
${ }_{1}^{1}$ Pontificia Universidad Católica de Chile, Departamento de Medicina Intensiva, Marcoleta 367, Santiago, Chile \\ 2 Instituto Nacional de Cardiología Ignacio Chávez, UTI de Cardio-Neumología, Juan Badiano No. 1 C.P. 14080, Ciudad de México, México \\ ${ }^{3}$ Hospital Clínico Universidad de Chile, Unidad de Pacientes Críticos, Santos Dumont 999, Santiago, Chile \\ Corresponding author: Glenn Hernandez, glennguru@gmail.com
}

Received: 29 Dec 2008 Revisions requested: 9 Feb 2009 Revisions received: 17 Apr 2009 Accepted: 4 May 2009 Published: 4 May 2009

Critical Care 2009, 13:R63 (doi:10.1186/cc7802)

This article is online at: http://ccforum.com/content/13/3/R63

(c) 2009 Hernandez et al.; licensee BioMed Central Ltd.

This is an open access article distributed under the terms of the Creative Commons Attribution License (http://creativecommons.org/licenses/by/2.0), which permits unrestricted use, distribution, and reproduction in any medium, provided the original work is properly cited.

\begin{abstract}
Introduction Central venous oxygen saturation $\left(\mathrm{ScvO}_{2}\right)$ has emerged as an important resuscitation goal for critically ill patients. Nevertheless, growing concerns about its limitations as a perfusion parameter have been expressed recently, including the uncommon finding of low $\mathrm{ScvO}_{2}$ values in patients in the intensive care unit (ICU). Emergency intubation may induce strong and eventually divergent effects on the physiologic determinants of oxygen transport $\left(\mathrm{DO}_{2}\right)$ and oxygen consumption $\left(\mathrm{VO}_{2}\right)$ and, thus, on $\mathrm{ScvO}_{2}$. Therefore, we conducted a study to determine the impact of emergency intubation on $\mathrm{ScvO}_{2}$.
\end{abstract}

Methods In this prospective multicenter observational study, we included 103 septic and non-septic patients with a central venous catheter in place and in whom emergency intubation was required. A common intubation protocol was used and we evaluated several parameters including $\mathrm{ScvO}_{2}$ before and 15 minutes after emergency intubation. Statistical analysis included chi-square test and t test.

Results $\mathrm{ScvO}_{2}$ increased from $61.8 \pm 12.6 \%$ to $68.9 \pm 12.2 \%$, with no difference between septic and non-septic patients. $\mathrm{ScvO}_{2}$ increased in 84 patients (81.6\%) without correlation to changes in arterial oxygen saturation $\left(\mathrm{SaO}_{2}\right)$. Seventy eight (75.7\%) patients were intubated with $\mathrm{ScvO}_{2}$ less than $70 \%$ and $21(26.9 \%)$ normalized the parameter after the intervention. Only patients with pre-intubation $\mathrm{ScvO}_{2}$ more than $70 \%$ failed to increase the parameter after intubation.

Conclusions $\mathrm{ScvO}_{2}$ increases significantly in response to emergency intubation in the majority of septic and non-septic patients. When interpreting $\mathrm{ScvO}_{2}$ during early resuscitation, it is crucial to consider whether the patient has been recently intubated or is spontaneously breathing.

\section{Introduction}

Central venous oxygen saturation $\left(\mathrm{ScvO}_{2}\right)$, a complex physiologic parameter, is being widely used as a resuscitation goal in critically ill patients [1-3], although several limitations may preclude a clear interpretation of its changes [4]. Early therapeutic interventions applied rather simultaneously after hospital or intensive care unit (ICU) admission, may affect the oxygen transport $\left(\mathrm{DO}_{2}\right)$ /oxygen consumption $\left(\mathrm{VO}_{2}\right)$ balance and $\mathrm{ScvO}_{2}$ in an unpredictable direction. The uncommon finding of low $\mathrm{ScvO}_{2}$ values in critically ill ICU patients may be explained by the predominately positive impact of these early interventions $[5,6]$.

More than $70 \%$ of critically ill patients undergo emergency intubation during ICU stay [6-8], a maneuver with strong and eventually divergent effects on the physiologic determinants of $\mathrm{DO}_{2}$ and $\mathrm{VO}_{2}$. The final impact of emergency intubation on $\mathrm{ScvO}_{2}$ may be unpredictable since it could potentially increase

ALI: acute lung injury; APACHE: Acute Physiology and Chronic Health Evaluation; ARDS: acute respiratory distress syndrome; $\mathrm{DO}_{2}$ : oxygen transport; EGDT: early goal directed therapy; $\mathrm{FiO}_{2}$ : fraction of inspired oxygen; $\mathrm{HR}$ : heart rate; ICU: intensive care unit; MAP: mean arterial pressure; $\mathrm{O}_{2}$ ER: oxygen extraction ratio; PEEP: positive end expiratory pressure; RR: respiratory rate; $\mathrm{SaO}_{2}$ : arterial oxygen saturation; $\mathrm{ScvO}_{2}$ : central venous oxygen saturation; SOFA: Sequential Organ Failure Assessment; $\mathrm{VO}_{2}$ : oxygen consumption. 
$\mathrm{ScvO}_{2}$ by blunting regional $\mathrm{VO}_{2}$, or eventually decrease it, particularly in hemodynamically unstable or hypovolemic patients, due to the negative effects of sedation and positive intra-thoracic pressure on cardiac output. Of note, $53 \%$ of septic patients were intubated during the study period in the earlygoal directed therapy (EGDT) trial [1], but the impact of this intervention on $\mathrm{ScvO}_{2}$ was not reported, nor has it been studied thereafter.

Our aim was to study the specific impact of this isolated maneuver on $\mathrm{ScvO}_{2}$ in critically ill septic and non-septic patients subjected to emergency intubation.

\section{Materials and methods}

This prospective observational multicenter study was performed in three university-affiliated hospitals between December 2006 and March 2008. The study was approved by the corresponding institutional review boards. Surrogates signed an informed consent for ICU treatment including the intubation procedure.

\section{Inclusion and exclusion criteria}

Adult patients with arterial and central venous catheters in place with a confirmed tip position in the superior vena cava, and in whom emergency intubation was required, were enrolled. Patients with acute neurological conditions and postcardiac arrest were excluded.

\section{Study protocol}

The intubation protocol started as soon as the intubation was decided. It included pre-oxygenation with $100 \%$ oxygen, etomidate $(0.1$ to $0.3 \mathrm{mg} / \mathrm{kg}$ ) or propofol $(0.5$ to $2 \mathrm{mg} / \mathrm{kg}$ ) for unconsciousness induction. Fentanyl (1 to $5 \mu \mathrm{g} / \mathrm{kg}$ ), midazolam (0.01 to $0.1 \mathrm{mg} / \mathrm{kg}$ ), and rocuronium (0.6 to $1.2 \mathrm{mg} / \mathrm{kg}$ ) were used for sedation and neuromuscular paralysis. Mechanical ventilation was started in all patients with the following initial settings: fraction of inspired oxygen $\left(\mathrm{FiO}_{2}\right) 100 \%$, respiratory rate (RR) 15 breaths/minute, tidal volume of $8 \mathrm{ml} /$ $\mathrm{kg}$ and positive end expiratory pressure (PEEP) $5 \mathrm{cmH}_{2} \mathrm{O}$. If hypotension developed during intubation, a bolus of $250 \mathrm{ml}$ of saline solution was infused and vasopressors were administered as required.

The study period was 15 minutes. Arterial and central venous samples were drawn for blood gases analysis immediately before and 15 minutes after intubation. Simultaneously, the following clinical variables were recorded: arterial pressure, heart rate $(H R)$, and $R R$. After the second blood gas samples, ventilator parameters were adjusted according to the particular patients requirements and current recommendations [2]. Blood samples were placed in ice cold water and transferred to the central laboratory to be analyzed by co-oximetry ( $A B L$ 725; Radiometer, Copenhagen, Denmark). Oxygen extraction ratio $\left(\mathrm{O}_{2} \mathrm{ER}\right)$ was calculated as $\mathrm{O}_{2} \mathrm{ER}=100 \times\left(\mathrm{SaO}_{2}\right.$ $\left.\mathrm{ScvO}_{2}\right) / \mathrm{SaO}_{2}$, where $\mathrm{SaO}_{2}$ is arterial oxygen saturation.
The clinical characteristics of the patients, demographic variables, cause of intubation, use of vasoactive drugs, and severity scores (Acute Physiology and Chronic Health Evaluation (APACHE) II and Sequential Organ Failure Assessment (SOFA)) were recorded at baseline. After the emergency, patients were classified as septic or non-septic, according to the predominant condition that led to the cardio-respiratory failure. Changes in $\mathrm{ScvO}_{2}$ were analyzed for the whole population and also individually for septic and non-septic subgroups.

\section{Statistical analysis}

Numerical variables were compared using Student's t test, and categorical variables were compared by chi-square or Fisher's exact test. Changes in variables $\left(\mathrm{ScvO}_{2}, \mathrm{O}_{2} \mathrm{ER}\right)$ were analyzed by a paired Student's t test. Correlation between changes in $\mathrm{ScvO}_{2}$ and $\mathrm{SaO}_{2}$ was performed with linear regression analysis. The SPSS 17.0 software (Chicago, IL, USA) was used for statistical calculations. Results are expressed as percentages or mean ( \pm standard deviation). A $P<0.05$ was considered as statistically significant. All reported $P$ values are two-sided.

\section{Results}

A total of 108 critically ill patients requiring emergency intubation were included in this study. Forty-two patients $(40.8 \%)$ were intubated for respiratory failure, 17 (16.5\%) for circulatory failure, and the remaining 44 (42.7\%) for mixed causes. Five patients were excluded from analysis because measurements could not be obtained in due time: two with difficult intubation and three for severe cardiovascular instability during the procedure. In these patients, samples were taken only after 35 to 50 minutes, and $\mathrm{ScvO}_{2}$ ranged from 59 to $65 \%$ with no improvement compared with pre-intubation values.

Baseline characteristics of the remaining 103 patients are shown in Table 1. Forty-eight patients (46.6\%) had severe sepsis (more frequently respiratory (43\%) and abdominal (40\%) sources). These patients had septic shock, communityacquired pneumonia, pancreatitis, and postoperative sepsis, with different organ dysfunction profiles including acute lung injury (ALI)/acute respiratory distress syndrome (ARDS) in 20 $(42 \%)$. Fifty (91\%) of the non-septic patients were of cardiogenic origin (including acute circulatory failure, acute coronary syndromes, pulmonary edema, pulmonary thromboembolism, life-threatening arrhythmias, and congestive heart failure).

At intubation, 41 patients were macro-hemodynamically stable without vasoactive drugs, and the others used either vasopressors or inotropes as shown in Table 1. Basal arterial lactate was $2.27 \pm 1.77 \mathrm{mmol} / \mathrm{L}$. Severe septic patients had been previously resuscitated according to Surviving Sepsis Campaign guidelines [2] including fluid challenge in all and vasopressors in 25 patients, mostly norepinephrine (Table 1). Source control was ongoing in all. In the cardiogenic patients, 
Table 1

\begin{tabular}{|c|c|}
\hline & All patients $(n=103)$ \\
\hline Age (years) & $58 \pm 17$ \\
\hline Gender male/female, $n /(\%)$ & $65(63.1) / 38(36.9)$ \\
\hline APACHE II score & $26 \pm 7$ \\
\hline SOFA score & $9 \pm 4$ \\
\hline Hemoglobin (g/dl) & $10.3 \pm 1.9$ \\
\hline \multicolumn{2}{|l|}{ Presence of severe sepsis } \\
\hline Yes, n (\%) & $48(46.6)$ \\
\hline No, n (\%) & $55(53.4)$ \\
\hline Cardiogenic, n (\%) & $50(48.5)$ \\
\hline \multicolumn{2}{|l|}{ Vasoactive drug use } \\
\hline None, n (\%) & $41(40)$ \\
\hline Vasopressors, n (\%) & $33(32)$ \\
\hline Norepinephrine & $20(19)$ \\
\hline Dopamine & $5(5)$ \\
\hline Inotropes, n (\%) & $29(28)$ \\
\hline Dobutamine & $17(17)$ \\
\hline Milrinone & $5(5)$ \\
\hline Levosimendan & $2(2)$ \\
\hline \multicolumn{2}{|l|}{ Vasoactive dose } \\
\hline Norepinephrine, $\mu \mathrm{g} / \mathrm{kg} / \mathrm{min}$ & $0.1 \pm 0.1$ \\
\hline Dopamine, $\mu \mathrm{g} / \mathrm{kg} / \mathrm{min}$ & $5.2 \pm 2.6$ \\
\hline Dobutamine, $\mu \mathrm{g} / \mathrm{kg} / \mathrm{min}$ & $4.6 \pm 1.9$ \\
\hline Milrinone, $\mu \mathrm{g} / \mathrm{kg} / \mathrm{min}$ & $0.42 \pm 0.21$ \\
\hline Levosimendan, $\mu \mathrm{g} / \mathrm{kg} / \mathrm{min}$ & $0.2 \pm 0.1$ \\
\hline
\end{tabular}

APACHE $=$ Acute Physiology and Chronic Health Evaluation; SOFA $=$ Sequential Organ Failure Assessment.

24 were receiving inotropic support with dobutamine, milrinone, or levosimendan (Table 1). Only nine patients were under vasodilator therapy. Hospital mortality for the whole group was $22 \%$.

No severe adverse events such as arrhythmias or cardiac arrest during intubation were registered. Thirty-three patients used vasopressors before intubation (Table 1), of whom 14 required a transitory increase in norepinephrine dose. Of the reminder 70 patients, 17 required one or two $8 \mathrm{mg}$ ephedrine bolus plus an additional $250 \mathrm{ml}$ normal saline bolus during the study protocol.

In the whole group, $\mathrm{ScvO}_{2}$ increased after intubation in 84 of 103 patients $(81.6 \%)$ from $61.8 \pm 12.6 \%$ to $68.9 \pm 12.2 \%(P$ $<0.0001$; Table 2 and Figure 1). $\mathrm{ScvO}_{2}$ increased also signif- icantly in both septic and non-septic patients (Table 2). Changes in $\mathrm{ScvO}_{2}$ were independent from changes in $\mathrm{SaO}_{2}$ as demonstrated by a non-significant correlation between both ( $r^{2}=0.014, P=0.242$; Figure 2). As a whole, 78 (75.7\%) patients were intubated with a $\mathrm{ScvO}_{2}$ less than $70 \%$ and 21 $(26.9 \%)$ normalized the parameter after this sole intervention.

We also explored the impact of the maneuver over $\mathrm{ScvO}_{2}$ according to pre-intubation values of $\mathrm{ScvO}_{2}$ and $\mathrm{SaO}_{2}$. We found a significant increase in $\mathrm{ScvO}_{2}$ in patients with baseline $\mathrm{ScvO}_{2}$ less than $70 \%$ independent of baseline $\mathrm{SaO}_{2}$. Only patients with $\mathrm{ScvO}_{2}$ more than $70 \%$ failed to increase the parameter after intubation (Table 3).

As a whole, oxygen extraction decreased in 56 patients $(54.4 \%)$ by more than $2.5 \%$, but increased more than $2.5 \%$ in 32 patients (31\%) compared with baseline. As expected, patients who decreased $\mathrm{O}_{2} \mathrm{ER}$ after intubation, exhibited higher pre-intubation respiratory rates $(30.7 \pm 6.3$ vs. $25.3 \pm$ 4.0; $P=0.047)$. Mean arterial pressure (MAP), HR, and RR decreased also significantly after intubation (Table 2 ).

Septic and non-septic subgroups showed the same trends in physiologic variables after intubation, except for a higher decrease in $\mathrm{O}_{2}$ ER in septic patients, and in MAP in the nonseptic subgroup.

\section{Discussion}

Our study demonstrates that emergency intubation markedly improves $\mathrm{ScvO}_{2}$ in both septic and non-septic patients. Changes in $\mathrm{ScvO}_{2}$ were consistent across the studied subgroups, regardless of the cause of intubation and baseline arterial oxygen saturation. In contrast, the effects on oxygen extraction were more variable. In almost $30 \%$ of the patients this sole maneuver increased $\mathrm{ScvO}_{2}$ over $70 \%$, a level considered as a resuscitation goal by current guidelines [2].

The role of $\mathrm{ScvO}_{2}$ as a reliable marker of global dysoxia has been widely accepted [1,2]. Nevertheless, no study has replicated the very low $\mathrm{ScvO}_{2}$ values of the EGDT trial [1]. Low $\mathrm{ScvO}_{2}$ values are present in less than $21 \%$ of ICU patients with septic shock or respiratory failure $[5,6]$. Interestingly, the study by van Beest and colleagues $83 \%$ of patients were already intubated before the first $\mathrm{ScvO}_{2}$ sampling [6]. In fact, our low pre-intubation $\mathrm{ScvO}_{2}$ values in septic patients closely resemble baseline data from the EGDT trial [1], although $\mathrm{ScvO}_{2}$ values after intubation are quite similar to those previously reported in the ICU setting $[5,6,9]$.

Is normalization of $\mathrm{ScvO}_{2}$ after intubation a reliable indicator of a successful resuscitation? Our data show that $\mathrm{ScvO}_{2}$, as expected, is highly sensitive to intubation. We believe that early normalization of this sole parameter after intubation should be interpreted with caution. Either an increase in $\mathrm{SaO}_{2}$ in some patients, or a decrease in cerebral and respiratory 
Figure 1

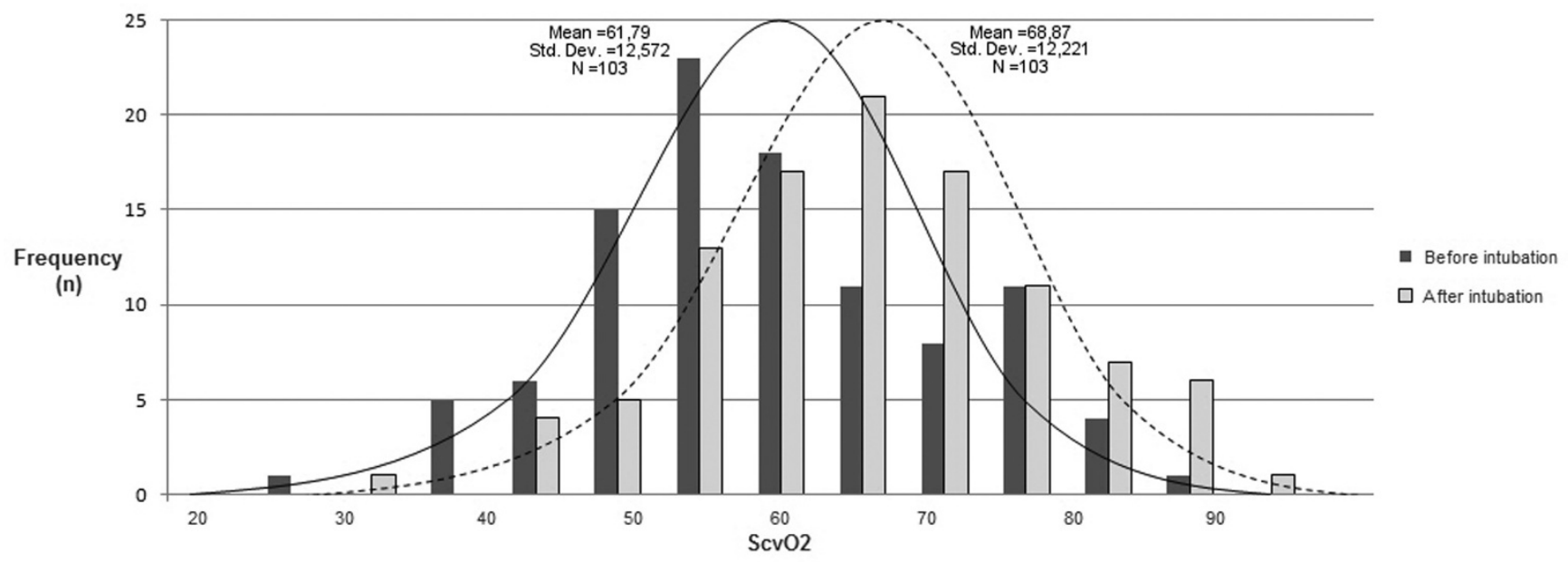

Distribution of central venous oxygen saturation before and after intubation. $\mathrm{ScvO}_{2}=$ central venous oxygen saturation.

muscles $\mathrm{VO}_{2}$, may both increase $\mathrm{ScvO}_{2}$, but not necessarily reflect an improvement in global perfusion. In concordance, a recent study challenged the sensitivity of a $\mathrm{ScvO}_{2}$ more than $70 \%$ as a marker of an adequate $\mathrm{DO}_{2} / \mathrm{VO}_{2}$ balance after resuscitation in the ICU setting [10]. Therefore, we strongly believe that a multimodal approach including other parameters such as clinical perfusion, venous-arterial partial pressure of carbon dioxide gradient or lactate, must be used to assess perfusion, particularly after intubation.
Although the aim of our clinical observational study was to evaluate the specific impact of emergency intubation on $\mathrm{ScvO}_{2}$ and not to explore the determinants of this response, some physiologic considerations are important. Several studies have shown that sedation and connection to mechanical ventilation can decrease oxygen consumption in the brain and respiratory muscles, the principal determinants of $\mathrm{VO}_{2}$ in the territories drained by the superior vena cava [11-17]. Supporting this concept, and as expected, we found that patients with higher pre-intubation RR exhibited more pronounced decreases in $\mathrm{O}_{2} \mathrm{ER}$ after the maneuver. Conversely, $\mathrm{DO}_{2}$ can

Figure 2

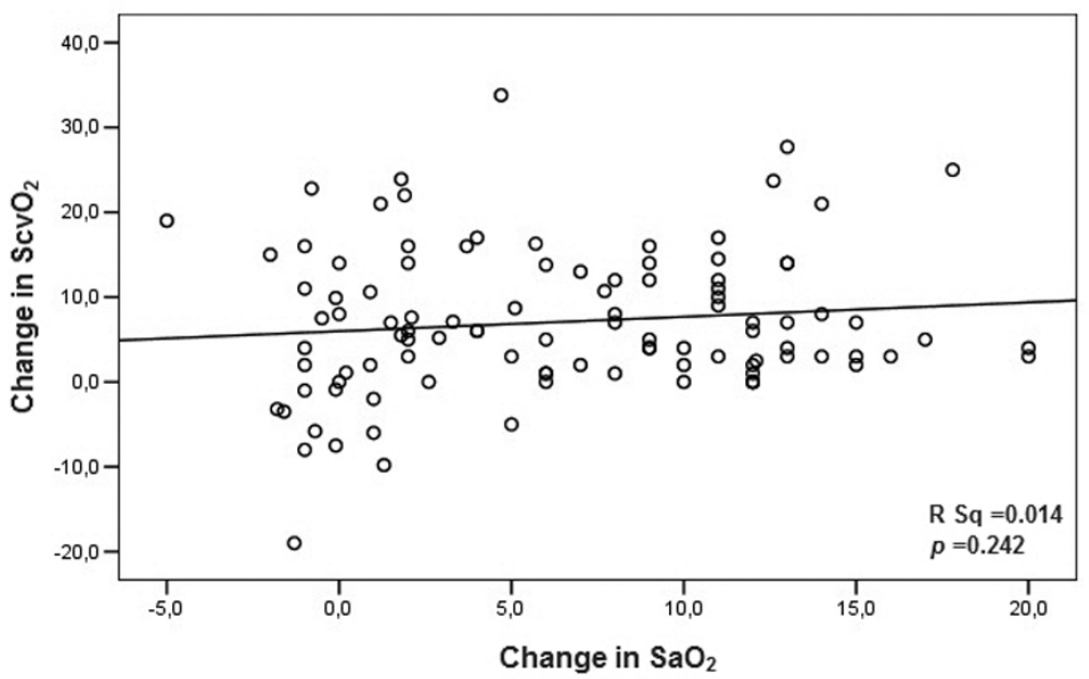

Correlation between changes in central venous oxygen saturation and arterial oxygen saturation after intubation. $\mathrm{SaO}_{2}=$ arterial oxygen saturation; $\mathrm{ScvO}_{2}=$ central venous oxygen saturation. 
Table 2

\begin{tabular}{llll}
\hline Study variables before vs. after intubation & & & \\
\hline & Before intubation & After intubation & $P$ value \\
\hline $\mathrm{SaO}_{2}(\%)$ & $90.6 \pm 7.5$ & $97.0 \pm 2.9$ & $<0.001$ \\
$\mathrm{O}_{2} \mathrm{ER}(\%)$ & $32.1 \pm 10.8$ & $29.2 \pm 11.6$ & 0.002 \\
Heart rate (beats/min) & $103.7 \pm 25.2$ & $96.4 \pm 23.1$ & 0.020 \\
Respiratory rate (breaths/min) & $29.1 \pm 6.2$ & $15.2 \pm 3.1$ & $<0.001$ \\
$\mathrm{MAP}(\mathrm{mmHg})$ & $67.8 \pm 19.6$ & $57.5 \pm 21.1$ & $<0.001$ \\
\hline
\end{tabular}

$\mathrm{MAP}=$ mean arterial pressure $\mathrm{O}_{2} \mathrm{ER}=$ oxygen extraction; $\mathrm{SaO}_{2}=$ arterial oxygen saturation.

$P<0.05$ considered as significant.

also be affected by emergency intubation and mechanical ventilation either by increases in $\mathrm{SaO}_{2}$ or changes in cardiac output. The increase in intra-thoracic pressure and decrease in sympathetic outflow induced by the maneuver favor a decrease in venous return, vasomotor tone, and cardiac output. Thus, sometimes divergent changes in $\mathrm{DO}_{2}$ and $\mathrm{VO}_{2}$ can be induced by emergency intubation and could probably explain the variable effect on oxygen extraction. Our results demonstrate that in the majority of patients subjected to emergency intubation, either septic or not, the predominant effect is to increase $\mathrm{ScvO}_{2}$, although this cannot be predicted a priori in individual cases. Therefore, an early measurement of $\mathrm{ScvO}_{2}$ after intubation may facilitate interpretation of further changes during $\mathrm{ScvO}_{2}$-guided resuscitation.
Our study has several limitations. To obtain a more comprehensive physiologic interpretation of $\mathrm{ScvO}_{2}$ changes, future studies should directly assess the effects of intubation on each of the determinants of $\mathrm{ScvO}_{2}$. Unfortunately, we did not measure cardiac output due to the extreme emergency context. In addition, it should be confirmed if these short-term effects persist over time and if early normalization of $\mathrm{ScvO}_{2}$ after emergency intubation truly represents a correction of global hypoperfusion.

Our results should not be interpreted as a mandatory recommendation to intubate every patient presenting with low $\mathrm{ScvO}_{2}$ during resuscitation. Some patients present severe hemodynamic instability after the maneuver. Clinicians must be aware of the inherent risks associated with emergency intubation, which should be balanced against the potential benefit.

Table 3

Changes in ScvO2 after intubation for different subgroups

\begin{tabular}{llll}
\hline & $\begin{array}{l}\mathrm{ScvO}_{2}(\%) \\
\text { Before intubation }\end{array}$ & After intubation & $P$ value \\
\hline $\begin{array}{l}\text { All patients } \\
\text { Presence of severe sepsis }\end{array}$ & $61.8 \pm 12.6$ & $68.9 \pm 12.2$ & $<0.001$ \\
$\quad$ Yes $(n=48)$ & $63.6 \pm 11.9$ & $71.1 \pm 12.0$ & $<0.001$ \\
$\quad$ No $(n=55)$ & $59.3 \pm 13.1$ & $65.6 \pm 11.6$ & $<0.001$ \\
According to baseline $\mathrm{ScvO}_{2}$ & & $64.8 \pm 10.8$ & $<0.2 \pm 8.1$ \\
$\quad<70 \%(n=76)$ & $56 \pm 8.4$ & & 0.181 \\
$\geq 70 \%(n=27)$ & $78 \pm 6.7$ & $61.5 \pm 11.4$ & $73.0 \pm 10.0$
\end{tabular}

$\mathrm{SaO}_{2}=$ arterial oxygen saturation; $\mathrm{ScvO}_{2}=$ central venous oxygen saturation.

$P<0.05$ considered as significant. 


\section{Conclusions}

$\mathrm{ScvO}_{2}$ increases significantly in response to emergency intubation in critically ill septic and non-septic patients, although it is not clear if this truly represents an improvement in global dysoxia. Our findings may contribute to explain the discrepancy between EGDT trial and ICU reports concerning the incidence of low $\mathrm{ScvO}_{2}$ values in heterogeneous critically ill patients. When interpreting $\mathrm{ScvO}_{2}$ during early resuscitation, it is crucial to consider whether the patient has been intubated.

\begin{tabular}{|l|}
\hline Key messages \\
- $\mathrm{ScvO}_{2}$ increased significantly in response to emergency \\
intubation in critically ill septic and non-septic patients. \\
- $\begin{array}{l}\text { Changes in } \mathrm{ScvO}_{2} \text { were consistent across the studied } \\
\text { subgroups, regardless of the cause of intubation and } \\
\text { baseline } \mathrm{SaO}_{2} \text {. }\end{array}$ \\
- In almost $30 \%$ of the patients, this sole maneuver \\
increased $\mathrm{ScvO}_{2}$ to levels considered as a resuscitation \\
goal by some current guidelines.
\end{tabular}

\section{Competing interests}

The authors declare that they have no competing interests.

\section{Authors' contributions}

$\mathrm{GH}$ conceived the study, and participated in its design and coordination and helped to draft the manuscript. $A B$ conceived the study, and participated in its design and coordination and helped to draft the manuscript. RC (Rodrigo Cornejo) conceived the study, and participated in its design and coordination and helped to draft the manuscript. RC (Ricardo Castro) conceived of the study, and participated in its design and coordination and helped to draft the manuscript. MR performed the statistical analysis. JR, HP, JLN, and IA recruited patients. All authors read and approved the final manuscript.

\section{Acknowledgements}

The study was funded by an institutional grant of the Departmento de Medicina Intensiva de la Pontificia Universidad Católica de Chile.

\section{References}

1. Rivers E, Nguyen B, Havstad S, Ressler J, Muzzin A, Knoblich B, Peterson E, Tomlanovich M: Early Goal-Directed Therapy Collaborative Group. Early goal-directed therapy in the treatment of severe sepsis and septic shock. N Engl J Med 2001, 345:1368-1377.

2. Dellinger RP, Levy MM, Carlet JM, Bion J, Parker MM, Jaeschke R, Reinhart K, Angus DC, Brun-Buisson C, Beale R, Calandra T, Dhainaut JF, Gerlach H, Harvey M, Marini JJ, Marshall J, Ranieri M, Ramsay G, Sevransky J, Thompson BT, Townsend S, Vender JS, Zimmerman JL, Vincent JL: Surviving Sepsis Campaign: International guidelines for management of severe sepsis and septic shock: 2008. Intensive Care Med 2008, 34:17-60.

3. Kapoor PM, Kakani M, Chowdhury U, Choudhury M, Lakshmy, Kiran U: Early goal-directed therapy in moderate to high-risk cardiac surgery patients. Ann Card Anaesth 2008, 11:27-34.

4. Bellomo R, Reade M, Warrillow S: The pursuit of a high central venous oxygen saturation in sepsis: growing concerns. Crit Care 2008, 12:130.
5. Bracht $H$, Hanggi $M$, Jeker B, Wegmuller N, Porta F, Tuller D, Takala J, Jakob SM: Incidence of low central venous oxygen saturation during unplanned admissions in a multidisciplinary intensive care unit: an observational study. Crit Care 2007, 11:R2.

6. Van Beest PA, Hofstra HH, Schultz MJ, Boerma EC, Spronk PE, Kuiper MA: The incidence of low venous oxygen saturation on admission to the intensive care unit: a multi-centre observational study in the Netherlands. Crit Care 2008, 12:R33.

7. Bernard G, Vincent J, Laterre P, LaRosa S, Dhainaut J, Lopez-Rodriguez A, Steingrub J, Garber G, Helterbrand J, Ely W, Fisher C: Efficacy and safety of recombinant human activated protein $C$ for severe sepsis. N Engl J Med 2001, 344:699-709.

8. Cornejo R, Downey P, Castro R, Romero C, Regueira T, Vega J, Castillo L, Andresen M, Dougnac A, Bugedo G, Hernandez G: High-Volume Hemofiltration as salvage therapy in severe hyperdynamic septic shock. Intensive Care Med 2006, 32:713-722.

9. Gattinoni L, Brazzi L, Pelosi P, Latini R, Tognoni G, Pesenti A, Fumagalli R: A trial of goal-oriented hemodynamic therapy in critically ill patients. N Engl J Med 1995, 333:1025-1032.

10. Vallèe F, Vallet B, Mathe O, Parraguette J, Mari A, Silva S, Samii K, Fourcade O, Genestal M: Central venous-to-arterial carbon dioxide difference: an additional target for goal-directed therapy in septic shock? Intensive Care Med 2008, 34:2218-2225.

11. Bloos F, Reinhart K: Venous oximetry. Intensive Care Med 2005, 31:911-913.

12. Moore KL: The Thorax. In Clinically Oriented Anatomy 3rd edition. Edited by: Keith L. Moore. Baltimore: Lippincott, Williams \&Wilkins; 1992:122-239.

13. Manthous CA, Hall JB, Kushner R, Schmidt GA, Russo G, Wood LD: The effect of mechanical ventilation on oxygen consumption in critically ill patients. Am J Respir Crit Care Med 1995, 151:210-214.

14. Field S, Kelly SM, Macklem PT: The oxygen cost of breathing in patients with cardiorespiratory disease. Am Rev Respir Dis 1982, 126:9-13

15. Ederberg S, Westerlind A, Houlz E, Svensson S-E, Elam M, Ricksten S-E: The effects of propofol on cerebral blood flow velocity and cerebral oxygen extraction during cardiopulmonary bypass. Anesth Analg 1998, 86:1201-1206.

16. Dempsey DT, Guenter P, Mullen JL, Fairman R, Crosby LO, Spielman G, Gennarelli T: Energy expenditure in acute trauma to the head with and without barbiturate therapy. Surg Gynecol Obstet 1985, 160:128-134.

17. Jubran $A$, Mathru M, Dries $D$, Tobin M: Continuous recordings of mixed venous oxygen saturation during weaning from mechanical ventilation and the ramifications thereof. $\mathrm{Am} J$ Resp Crit Care Med 1998, 158:1763-1769. 